MILENA GAMMAITONI ${ }^{1}$

\title{
A CASE STUDY: ROME'S ORCHESTRA DI PIAZZA VITTORIO AND THE SOCIAL FUNCTION OF MUSIC
}

\begin{abstract}
The research presented here is based on studies of the sociology of music, as well as on analyses of the dynamics of immigration. This explored some of the social dynamics and actions of a multi-ethnic orchestra founded and operating in Rome. The purpose of the study was to examine this orchestra as an example of good practice regarding intercultural integration and was the criterion by which we chose to analyse the Orchestra di Piazza Vittorio, founded in 2002 by Mario Tronco in one of Rome's central multi-ethnic districts, the Esquiline. The question posed here is whether the creation of a multi-ethnic orchestra can act as an alternative model which, by means of the socialisation process, redefines and rediscovers the age-old relational and integrating functions of music, availing of the collective memory, identity, heritage and varieties of music, without forfeiting its own identity.
\end{abstract}

Key words: sociology of arts, identity, life stories

\section{INTRODUCTION}

Immigration is the demographic humus of peoples whose negative population growth-rates make it impossible for them to go on sustaining a welfare state.

Young Europeans agree that the creation of conditions for total economic, political and social integration is mandatory: this, however, is a statement of principle. Italy and, more in general, the countries of

${ }^{1}$ PhD; University of Roma Tre; milena.gammaitoni@uniroma3.it. 
Southern Europe, are obliged to address the problem of open frontiers; the city of Rome, in particular, witnesses an increase in immigration rates higher than the national average. ${ }^{2}$

According to a recent European research project, it is migration from the Balkan and ex-Soviet-Union areas which creates the greatest diffidence towards immigration in countries alike. ${ }^{3}$ Greater degrees of acceptance are expressed towards immigrants from Eastern Europe, and/or from countries practicing a similar religion, as is the case of the Filipino and Polish women who move to live in Italy. Attitudes vary when it comes to people from developing countries. However, of the EU countries, it is in Italy that the migratory phenomenon gives rise to the greatest levels of concern as it is associated with issues of law and order and personal security. A little less than one third of EU citizens consider immigration a danger or a threat; $26 \%$ fear for their cultural and national identity; and 33\% for employment and personal safety. About $60 \%$ of the citizens of both groups believe that their "country is no longer able to cater for immigrants, even if legal."

It was in similar conditions that the musicians - who had been professionals for generations - of Rome's Orchestra di Piazza Vittorio, came to meet the unknown challenge of migration to Italy, imagining it as an

${ }^{2}$ The data published by the Italian national statistics office, Istat, reveals that in the province of Rome the resident foreign population rose in one year from 228,205 to 278,540 (+22.1\%). In Italy, the entire foreign population listed with the national registry office rose by 268,408 persons, that is, by $10 \%$, increasing from $2,670,514$ to $2,938,922$. The province of Rome, with its 50,535 new entries, accounts for one fifth of Italy's aggregate increase. The province stands out also for the high impact (6.9\%) of immigrants on the overall local population $(4,013,057)$. While the national average is $5 \%$, that of the Lazio region stands at $6 \%$, ranking among the first of the 20 Italian provinces for presence of an immigrant population. Rapporto Caritas, Dossier statistico Immigrazione, 2015. According to the ISMU foundation for multiethnicity's Thirteenth Report on immigration, the phenomenon has continued to grow in Italy, and, from 2006 to the $1^{\text {st }}$ January 2007 , rose by $8.7 \%$. See ISMU, Tredicesimo Rapporto sulle migrazioni, 2007, Milan 2007, p. 41.

${ }^{3}$ The survey led by G. Campione, Department of Statistics and Geopolitical Analyses of the Local Economy, University of Messina, has sought to identify the cultural, political, economic and institutional factors that foster and inhibit the worsening of the migratory phenomenon. The aforementioned survey, conducted between December 2005 and January 2006 and involving 8,000 respondents, was carried out by some of the most authoritative European research agencies and covered a population sample from five European countries: France, Germany, Great Britain, Italy and Spain. 
opportunity-packed, culturally and musically amenable occasion. ${ }^{4}$ For these musicians, music represented a total social truth in a complex and fragmentary reality, where social distance and demonstrations of intolerance on the part of the autochthonous residents were challenges to be met alongside the task of attracting politically and socially heterogeneous audiences to their concerts. The creation of the Orchestra di Piazza Vittorio is also a statement of courage and enterprising ability on the part of each single musician, because neither the Italian State nor other public institutions support it financially.

\section{THE SOCIOLOGY OF MUSIC}

When dealing with a sociological study of music, it is of primary importance to define what music means, the sense in which the term is used and the areas which sociology can and should explain and interpret the many uses to which the musical phenomenon may be put and all the implications involved, as well as predicting its existence and development. This is particularly important when studying contemporaneity; to this must be added direct sources such as the life stories of musicians with different social-musical identities, as in the case of the Orchestra di Piazza Vittorio.

Marcello Sorce Keller in Musica e Sociologia considers it a necessary precondition that the sociology of music is emancipated from ethnomusicology, a story that reiterates and repeats itself, like the birth of sociology as a science which required its release from anthropology (although it proved to be necessary that the two disciplines continue to feed each other).

Although it is from ethnomusicological studies that one thinks of drawing when seeking to understand the development of a multi-ethnic orchestra, it is by doing so that one also discovers that ethnomusicology has not addressed the innovations that the new kinds of music introduced to the country by immigrants have produced in Italy. ${ }^{5}$ Italy's foremost ethnomu-

${ }^{4}$ It is important to note that migration brings to Italy increasing numbers of refugees and segments of foreign populations who are professionals with high-level educational qualifications. The social composition of the Orchestra di Piazza Vittorio reflects this situation exactly. See E. Pugliese, M.I. Macioti, Immigrati e rifugiati in Italia, Rome 2006.

${ }^{5}$ See Aa.Vv., Enciclopedia della musica, vol. I-IV, Turin 2006. 
sicology studies concern popular traditions; the musicologists themselves consider it a rather complex undertaking to approach the mix of ethnic music, directed and co-created by that rather peculiar conductor of the Orchestra di Piazza Vittorio, Mario Tronco, a pop musician whose position bears little resemblance to that of a classical conductor.

When must sociologists take an interest in and commit themselves to this kind of study?

Luciano Gallino, in the Dizionario di Sociologia, places the study of music within the field of the sociology of art, in that music shares with art "the relationships existing between the contents, forms, genres, institutions, individuals, the market of artistic production (sonata, concerto, symphony ...) and the main structures of the society within which production and sociality are generated, paying particular attention to the structure of the social classes, their ideology, as a prominent conditioning factor of musical production and its fruition." 6

Gallino attributes some specific social functions to music, such as those associated with communication (expression of collective feelings) and social control.

Music has peculiarities that the other arts do not possess, in so far as it is an "extremely ambiguous system of signs"; as a result, one is often led to make generic claims, namely "speculative effusions". Besides, it is not possible to underestimate the fact that developments in technology, systems of production, musical reproduction, as well as the transmission of music through radio and television, have turned music into a form of mass communication.

By way of example, at the end of the 1980s, Roberto Cipriani pointed out that it was far cheaper to buy a cassette recording of classical music than a ticket for a concert. ${ }^{7}$ Following up in this statement by Cipriani, we can say that, at the moment, the diffusion of music is exploited more and more for strictly economic and musically reproductive reasons. Indeed, one example is the inversion of the price trend: today, unlike the 1980s, a CD often costs more than a concert ticket. ${ }^{8}$

${ }^{6}$ L. Gallino, Dizionario di Sociologia, Turin 1978, p. 37.

${ }^{7}$ F.C. Ricci, R. Cipriani, I/ consumo musicale in Italia, il caso degli arrangiamenti, MiIan 1989.

${ }^{8}$ It is no coincidence that, from the beginning, purely commercial sites were chosen to favour the spread of music to general audiences: the first concert hall was set up in 
Music can act as a tranquilliser and a distraction; it is a medium of emotional expression and the integration of youth movements, as Ferrarotti explains, and has become, itself, a collective movement. ${ }^{9}$

Although, broadly speaking, these are the categories within which sociological studies may move, some sociologists find this hard to do. Again, Luciano Gallino writes on this topic that:

The fact that the task of the sociology of music is of unusual difficulty and amplitude, justifies the limited results achieved so far. ${ }^{10}$

On the contrary, Vera Zoldberg, the contemporary American sociologist, explains that, today, scholars have discovered the socially structured nature of art, cultural institutions, artists and audiences, and the fact that their critical function with regards to existing systems is of vaster intellectual weight than used to be imagined, even in Adorno's day. ${ }^{11}$ For these reasons, intellectual uncertainty is an indicator of the inadequacy of the theories and the lacunae found in the available data.

One might ask why music should be "highlighted" from a sociological point of view when musical analyses, theories of styles and genres, social history, provide a far safer and more obvious kind of access to it.

The answer to this question is one of the aims of my investigation - to show the usefulness of sociological attention of the musical environment, where the focus, one should never forget, is the human being, namely: the composer, the performer, the "employer", and the beneficiary.

Franco Ferrarotti tells us that "a society without artists is lost . . . a society that lacks free, autonomous artists is lost. Their indicative ability is directly proportionate to the extent of their autonomy," recalling that "the totally free, unbridled artist is an artist without terrain, outside of society." 12

Starting from the complex theoretical framework of the sociology of contemporary music, this study of the Orchestra di Piazza Vittorio summons up a variety of ranges in a multidisciplinary approach that may help

Germany by a group of merchants from Leipzig, who, in 1770, availed of a hotel, while in 1781 a cloth merchant's home was converted into a concert hall.

${ }^{9}$ F. Ferrarotti, Rock, rap e l'immortalità dell'anima, Naples 1997.

${ }^{10}$ Ibid.

${ }^{11}$ V. Zoldberg, Sociologia dell'arte, Bologna 1990.

12 F. Ferrarotti, Homo Sentiens, Naples 1995, p. 3. 
resolve problems within the discipline itself. My research is based on the correlation between the different social dimensions found within the life of the orchestra itself: thus, a multi-ethnic group which practices the musical profession while becoming integrated in the country to which its members have emigrated, even socialising with other ethnic groups; at the same time, the orchestra is acquiring increasing visibility and success with Italian audiences of all ages. Finally, the orchestra is creating a new kind of music, by interweaving the traditional melodies and rhythms of its members' different countries of origin, and jumping the old fences existing between diverse kinds of music: folk, classical, jazz, light and rock.

It was actually Max Weber, in his study of the development of music in the Western world, who pointed out that the choice to use certain sounds made by a given culture reflects some of the essential characteristics of that same culture. Indeed, the sociologist hastened to emphasise the fact that polyphony was not an invention of the European Middle Ages, but was already present in sub-Saharan Africa, in Indonesia, where the people's musical ear was more highly developed, more sensitive than that of the European peoples. ${ }^{13}$

Enrico Fubini underlines the fact that the evolution of music has followed internally more autonomous routes than those of the other arts. Literature, painting and architecture, have followed more coherent, more academic channels and pathways more independent of extra-cultural contributions. Musicians have succeeded in transferring inventions from the world of learned music into folk music and those from the oral into the academic tradition. Furthermore, there is considerable temporal-vertical mobility in the world of music, in the transmission of its heritage from one generation to another; there is also an unusual degree of spatial-horizontal mobility from one country to another, more so, perhaps, than in the case of the other arts.

Adorno, in this regard, speaks of a universal language. There is no need for an affinity between musical language and nations, "even civilizations that are poles apart reach reciprocal understanding through music."14

It is indeed true that, on the one hand, the transmission of music seems to require a maximum of specialization, of doctrine. However, it is also true

\footnotetext{
${ }^{13}$ See M. Weber, I Fondamenti Razionali e Sociologici della Musica, in: idem, Economia e Società, Milan 1995.

${ }^{14}$ See W. Adorno, Introduzione alla sociologia della musica, Turin 1971, p. 189.
} 
that thanks to its easy memorization, it is spread and passed from people to people, reaching beyond political, geographical and linguistic barriers and boundaries with an agility and dynamism unknown to the other arts. This mode of development and mobility so different in time and space from that of the other arts, this ability to combine different elements, different styles, different musical civilizations, finds a possible interpretation in the fact that music seems to have an impact upon people more immediate and greater than any other socio-cultural phenomenon. There remains the fact that the history of music, and with it, that of the musician, is considered and continues to be regarded as marginal. In the field of sociology, in particular, music remains a culture difficult to identify on the basis of institutional channels. As a form of culture, meaning subjective knowledge, it lends itself to being a pastime, a form of play, of theoretical wisdom, of philosophical speculation, a profession. Music as an expression of a culture, as a means of cultural identification, as cognitive heritage, does not seem to have acquired a similar degree of legitimacy. It lends itself to becoming the subject of a proliferation of sectorial, specialist studies, independent of each other, studies that are little known because they are difficult for non-specialists to access.

Luigi Del Grosso Destrieri speaks of the musicalization of our societies, where musicalization means that there is almost no moment or occasion of our daily lives that is not accompanied by some explicit or implicit aspect or other of music, perceived at conscious or subliminal level. ${ }^{15}$ Music has invaded contemporary society as a mass phenomenon profoundly affecting both the producer-performer and the consumer.

In an attempt to analyse what music produces in human society, Merriam attributes a number of universal functions to it, which do not regard the ability to communicate and understand the sense and meaning of music as such, but, as the author states, its contribution to social integration which occurs because it satisfies the need to participate in something that is familiar to everyone (starting with the mother's heart-beat that every child hears during the months of gestation), something that conveys certainty of membership of a group that shares values, a way of life and art forms. ${ }^{16}$ As such, it tends to renew solidarity, to reduce social inequality and unify society, in a constant manner.

${ }^{15}$ L. Del Grosso Destrieri, Sociologia delle musiche, Milan 2002.

${ }^{16}$ A.P. Merriam, Antropologia della musica, Palermo 1983. 
A further step needs to be taken, namely; the sociological study of music and of the musician will be achieved in full only when the social-experiential origins of musical life are acknowledged. For Antonio Serravezza, this approach is the premise for an analysis which goes beyond metaphysical speculation. It is only by demystifying origins and meanings that one can draw closer to humanity:

Recognition of the social nature of the musical experience is of the utmost importance, because it implies abandoning inadequate, mystifying conceptions of music. If we admit that music has a social origin, we implicitly acknowledge that it is born in the human world and takes part in events and transformations accomplished in this world, and therefore, is not, as it is often held to be, a heavenly messenger bearing news to men of a perfect reality, stable in all its meta-historical eternity. ${ }^{17}$

This would bring considerable benefits to scholarship once beliefs imposed only by the metaphysical pathos that animated them, and their power of suggestion, were dismissed. In this way, it is possible to address the topic of music, also with a view to analysing the Orchestra di Piazza Vittorio on a more manageable terrain as it is "less cluttered with metaphysical residue and more accessible to reason and its tools." 18

\section{RESEARCH INTO THE ORCHESTRA DI PIAZZA VITTORIO}

This research project, which began from the moment the orchestra was founded in 2002, was brought to a conclusion in $2015 .{ }^{19}$ It was aimed, initially, at exploring this example of best practice whose aim it was to integrate various immigrant ethic groups. Later on, however, it was aimed at focusing on the inevitable transformation of the orchestra and on the originality of its musical creation. The Orchestra di Piazza Vittorio is the

${ }^{17}$ A. Serravezza, Sulla nozione di esperienza musicale, Bari 1971, p. 125.

${ }^{18}$ Ibid.

${ }^{19}$ A qualitative research methodology (case studies) was applied, availing of tranches de vie from the lives of all the musicians (with focused interviews) which were integrated through the use of research and observation techniques, typical of the field of ethnography and of grounded theory. A book by M. Gammaitoni, L'Orchestra di Piazza Vittorio, storia e storie di vita, will soon be issued by Laterza in Rome. 
brainchild of Mario Tronco and is located in Rome in one of the city's central, multi-ethnic areas, namely the Esquiline. ${ }^{20}$

Using structured observation of pre-concert rehearsals, I followed the professional coexistence of this community of artists (each one with his/ her particular, heterogeneous education and life experience) who happened, syncretically, to give life to an orchestra located in a district of Rome famous for its demographic (residential-ethnic) transformations.

From being a typically native-Roman district, the Esquiline has become the residential and commercial home of immigrants (today, of Chinese, mostly, followed by Koreans, Bengalese and Egyptians), giving birth to a large, internally very heterogeneous community of immigrants, characterised by conflict among ethnic micro-communities, creating diversity within diversity (diversity with regard to Rome's autochthonous population and diversity among the different immigrant ethnic groups).

As Francesco Piccolo writes:

What is true is that unlike many other areas of several other cities, here, distance, that is, the difference between one's own life and that of the human family has been shortened to the utmost. Instinctively most communities tend to create separation between themselves and the reality, aspiring to be better than it. Here no. Here, there is complexity. The difficulties of coexistence, tension and gestures of sharing. That is what the human family is like in Piazza Vittorio, like the rest of the world. ${ }^{21}$

The Esquiline district brings together the stuff of stories and presences that testify to the profoundly hybrid nature of our cities, opening up prospects of a future state, that fascinates some, arouses anxiety in many, but also involves the rejection of minorities which concerns everyone. It suffices to walk through Piazza Vittorio (the neighbourhood's central square) to fully understand concepts such as multi-cultural, multi-ethnic, plural, hybrid and intercultural society.

Analysing the life of a musical group that unites a micro-community, as an example for larger national and international communities, may be a social challenge capable of triggering new relational dynamics, redefining the concept and practice of social distance, availing of the art of music

\footnotetext{
${ }^{20}$ A musician from the Avion Travel musical group.

${ }^{21}$ F. Piccolo, Noi che all'Esquilino ci viviamo, in: Aa.Vv., Prove d'Orchestra, Rome 2006.
} 
used to harmonise differences. This may be the means by which to discover and appreciate cultural diversity, availing of the interplay between the different sounds that characterise the musical instruments of diverse cultural traditions.

The originality of this orchestra, and what makes studying it interesting, lies in the fact that this is a group of professional immigrant musicians from several countries (India, Romania, North Africa, South Africa, Brazil, Ecuador), each of whom complements and enriches the musical ensemble by playing the original instruments of his/her native land.

At present the orchestra consists of 16 permanent musicians, though its make-up can vary according to the repertoire played. Some of them have lived in Rome for quite some time and have adapted themselves to working in jobs remote from the musical profession. Mario Tronco devoted himself to setting up the orchestra by holding authentic auditions, with the intention of hiring only great musicians as they were expected to assume the task of diffusing a new image of the immigrant, namely: one of a serious professional capable of entering into a constructive relationship with the autochthonous residents and becoming an asset for the city of Rome first and, more ambitiously, for Italy and the rest of the world. Indeed, that is precisely how things stand, because the orchestra comprising Africans, Indians, South Americans and Europeans is a union of different musical genres: if a Moroccan sings a song of his/hers, all the others improvise and adapt their own music and instruments to those notes.

Therefore, the first musicians arrived; some of them at random, others because they were already known in Rome and were called on to join. Many stay, others abandon or are forced to abandon the orchestra because of recent Italian regulations governing immigration. Originally, the orchestra could not afford to "hire" the musicians permanently. Consequently, this made it impossible for many who worked only occasionally - as many musicians do - to obtain a work permit entitling them to residency status.

Mario Tronco describes the disorder underlying the initial phase: how the idea of a multi-ethnic orchestra with a precise address took root, in a city like Rome, in an extremely problematic yet highly symbolic, typically Roman neighbourhood like the Esquiline. It is one which, in the last 15 years, has become a neighbourhood of urban decay and where immigration is experienced by the native Italian residents as a syndrome of siege and widespread crime. As he relates: 
How was the Orchestra born? The idea cropped up just like that, a bet with Agostino Ferrente. Almost by chance I said "It would be lovely to create an orchestra of foreign musicians living here in Rome" and from that moment on, Agostino pestered me, we spoke of nothing else. I spoke about it to my wife, Francesca, and she was enthusiastic about the idea. Back then the Apollo 11 project had just come to light and we felt the urge to do something concrete for our area, in our area. One evening Agostino, Annamaria Granatello (an Apollo 11 project designer) and I happened to be at the home of Monique Veaute, the organiser of the Roma Europa Festival, and we proposed a concert by the orchestra which did not as yet exist. She was passionate about it and she got us into splendid, deep trouble by asking us to play on the evening of the $24^{\text {th }}$ November 2002, at the Festival's closing event. ${ }^{22}$

Tronco's words convey clearly the importance of community life to the orchestral experience. It is not a question of meeting, as happens with more classical types of orchestras, for purely technical, interpretational rehearsals. Here, the meetings between the musicians are creative from a musical-compositional point of view, and are existential encounters where life histories, different musical knowledge and customs are exchanged, together with the everyday problems regarding the city where the members of the orchestra live, problems they all share.

Mario Tronco plots the genesis of the orchestra beginning from his own wonder at having been able not only to create it, but also at the unexpected and unforeseeable world that it has revealed over time:

Since the birth of the orchestra what has happened that you would never have imagined? I never expected such great involvement on the part of the musicians. They are extremely generous, an inexhaustible source of ideas and proposals. There is healthy competition among them but it never becomes individualism and they play together as if they had known each other all their lives. I never expected the work continuity we are experiencing. I never expected to see people so happy at the end of our concerts.

What foreign words have you learnt from the musicians? In reality, none, because they all speak a rather amusing kind of Italian; in actual fact, a new language is emerging within the orchestra, one we use during rehearsals and concerts. To say lascialo ['leave it', pronunciation /la-shah-lo/], we say accialo ['lace/fasten it', pronunciation /latch-ah-lo/], a word invented by Omar who,

22 Interview with Mario Tronco published at www.orchestradipiazzavittorio.it. If not pointed otherwise, all further citations come from this source. 
as a Cuban, finds it practically impossible to pronounce /sh/. The nickname of the orchestra's tour manager, Francesca, is "mama toilet" because the Indians call her that. Bilal, on the other hand, instead of simpatico and antipatico says "sempepatico" and "enpepatico".

... What I liked immediately about the orchestra was the fact that many of its members are authors, many of them write what they perform. There is even a group of seven members emerging within the orchestra and I hope that there will be further experiments of this kind.

How do the contributions of the various musicians blend? In an extremely natural manner; the musicians are curious. After the first few rehearsals, each one of them invented and assumed a role for him/herself. Although they all work towards a shared final goal, they all play solo parts.

Since its foundation the orchestra has rehearsed at the Galileo Galilei senior secondary school in the Esquiline area and the Roman population has always been invited to listen, free of charge, to its open rehearsals. The orchestra holds concerts in Italy, Europe and in the USA. The film by Agostino Ferrente entitled Orchestra di Piazza Vittorio made in 2006 was awarded prizes by the critics and screened in many first-run cinema theatres. The orchestra has recorded three different CDs distributed by major retail chains.

The orchestra was born also thanks to the support and cooperation of the area's Apollo 11 association set up to revalue the Esquiline district, with the intention of establishing peaceful and active coexistence among the various cultural groups residing in the neighbourhood. Thanks to the pressing demands made by the association on the Municipality of Rome, restoration work was begun on the neighbourhood's abandoned archaeological sites, on the Apollo (the theatre which it was hoped might become the permanent seat of the orchestra), on historically significant buildings, and on bad roads (to control the noise pollution produced by public transport unsuited to driving through the narrow streets of neighbourhood). ${ }^{23}$

The director of the film, Agostino Ferrente, president of the Apollo 11 association, describes the idea of the orchestra and the almost propitiatory role of the film, the first scenes of which were shot before orchestra actually existed. Indeed, Ferrente filmed every effort made, every audition held, every meeting with each new musician, without knowing what the outcome might be:

${ }^{23}$ In 2007 Rome's Municipal authority sold the Apollo theatre to a private purchaser. 
- You said that when you began shooting, the Orchestra did not exist as yet.

- Yes. In actual fact, initially there was only the idea of creating an orchestra beginning from scratch and the idea of filming too cropped up, without knowing how it might end...

Normally when you make a documentary you begin by falling in love with a story or a situation and decide to narrate it; in our case I'm not saying that the film was born before the reality but the two things came to light more or less in parallel and stimulated each other. Mario and I, like some modern-day Don Quixote and Sancho Panza rode around Rome on a Vespa talking about this utopia, about a dream that might come true. And I must say that, had it not been for the eye of the camera, all the disappointments, unfulfilled expectations, the difficulties we encountered would have been far harder to bear. Its presence made it the third accomplice: had all else failed, there would have been a film at least.

All told, it was as if the allied gaze of the hypothetical audience hidden behind that camera gave us strength, reassuring and protecting us ... On the contrary, with hindsight, we like to think that the tenacity that made us want to give the film a happy ending and that imaginary audience which, meanwhile, rooted for us, acted as extra stimuli to the achievement of the enterprise, maybe even its determining factor.

One may hypothesise that the orchestra built a utopistic community, where it was possible to achieve individual, relational and social ambitions. This is clear from the statements and aspirations of the various musicians. What prevails is enthusiasm along with musical curiosity towards what is different, towards the native culture of each, while remaining well aware that the orchestra is unique, not only for Italy but also for the world, due to its way of conceiving diversity, its collaborative approach to work: a complex kind of sociality.

By way of example, I shall now quote a few brief testimonies provided by some of the musicians, from which it is possible to evince their great professional commitment, their musical expectations and those related to their success/visibility in the rest of the world. This is all joined, however, to a note of wonder at having been able, by means of this union of miscellaneous cultures, to compose music together for which they have not as yet found a "label" capable of defining it.

The work of these musicians is governed by respect and the urge to discover other leading people musically and existentially, therefore, to rediscover themselves in the light of a pluralist encounter, where every voice finds a space: 
Ziad Trabelsi (Tunisia): The orchestra is a turning point in my life: Mario Tronco is an open-minded musician who accepted my creativity immediately.

Now, with the orchestra, we have passed on to the mature phase and, under the guidance of Mario and Pino, I am beginning to discover myself as an author, above all as a composer. For the western ear the notion of composition is very different (from that of Arabian music); besides having a gift one needs to follow some precise parameters that are not "protagonists" in eastern music. This new experience involves a dialogue between harmony and melody. Besides, this harmony has created a dialogic bridge which means integrating reality with all its problems, including that of the residency permit.

Houcine Ataa (Tunisia): The orchestra is unique because it has no equal, with so many international musicians. Each one has his/her own role, his/her musical particularity.

Gaia Orsoni (Italy): The orchestra? Who could have ever imagined that I too would belong to the group! A dream come true because playing on stage with international musicians is bonded by a love for music, human relations, esteem and friendship. The orchestra's music is one that stems from a mix of many elements, difficult to find together. It is a truly unique experience.

In 2010 the orchestra began launching its grand musical challenge, namely: first a rewriting of Mozart's The Magic Flute in 2012, then an adaptation of Bizet's Carmen in 2014, and the creation of an oratorio entitled Credo as a dialogue between different religions. Mario Tronco explains:

From the beginning the orchestra received a number of signs, experienced some small coincidences which indicated the road to follow. It was great to receive an invitation from Teatro dell'Opera just when we were beginning our Magic Flute adventure, the brainchild of Daniele Abbado used to open his Magic Flute project held in the streets of Reggio Emilia during a white night event. The overture and those first 30 minutes of music brought it home to me that it was possible to imagine Mozart's work as part of the popular oral music tradition. The rewritten opera followed the style and peculiarity of the orchestra and, therefore, it is in no way disconcerting that Papageno sings in Senegalese instead of German. This is the route we have followed and which has paved the way towards potentially infinite new possibilities for the orchestra.

These experiments have led to previously un-trodden symbolic pathways of action, operating upon four levels, namely: that regarding the construction of the signs and symbols contained in the lyrics; that of 
the symbolic reflection of emotional and cultural meanings; that mirroring other modes of behaviour and cultural values; that concerning the deepest, universal symbolism represented in the West by The Magic Flute, here revisited according to the feelings and musical languages of the many cultures present in the orchestra of Piazza Vittorio.

Moreover, John Shepherd relates musical languages and social structures, underlining the dynamic nature of their rapport:

Music is not a closed informational symbolic mode of communication relative only to emotional, vital, sentient experiences but an open mode which, by means of its essential structural nature, is uniquely suited to revealing the dynamic structuring of social life of which the material forms are only an aspect. ${ }^{24}$

In sociological literature, the group has always been considered an important concept capable of mediating between the individual and society. Thus, in the case of the orchestra we find a microcosm that delineates conditions while being conditioned by the structure of the macrocosm where it operates and to which proposes itself.

By tradition, the sociology of the arts promotes both an exogenous and endogenous study of artists' lives with a view to understanding social change and shifts in the values that underpin the aesthetic effect of works of art, pursuing individual or group pathways.

When the function of musicians was separated from that of poets (united at the time of the ancient Greek bards), they were obliged to wander, to use their wits to survive during hard times: a condition typical of the migrant. Furthermore, a phenomenological interpretation might investigate the relationship existing between musicians and their bodies as media through which to relate to the world with their musical instruments, that is, relationships as a way of declaring their identity to the world external to themselves.

The creation of a multi-ethnic orchestra lends itself to becoming an alternative model (proactive, both inside and outside the group) thanks to an organisational process of re-socialization, not of assimilation, that redefines social cohesion, recovering the age-old relational-integrative functions of music from an identitarian multiplicity.

${ }^{24} \mathrm{~J}$. Shepherd, Whose music? A sociology of musical languages, New Brunswick and London 1977. 


\section{BIBLIOGRAPHY}

Aa.Vv., Enciclopedia della Musica, Turin 2006.

Aa.Vv., Prove d'Orchestra, Rome 2006.

Adorno W.Th., Introduzione alla sociologia della musica, Turin 1971.

Andreoli V., in: Giovani di oggi, musica di sempre, Atti del Convegno, Milan 2002, p. 113.

Danese G., Interazioni tra musica e società, Teramo 1999.

Del Grosso Destrieri L., Sociologia delle musiche, Milan 2002.

Elias N., Sociologia di un genio, Bologna 1991.

Fabbri F., Il suono in cui viviamo. Saggi sulla popular music, Milan 2008.

Ferrarotti F., Homo Sentiens, Naples 1995.

Ferrarotti F., Rock, rap e l'immortalità dell'anima, Naples 1997.

Ferrarotti F., La funzione della musica nella società tecnicamente progredita, Rome 2010.

Ferrarotti F., La musica post-moderna ha un cuore antico, Rome 2010.

Ferrarotti F., La vocazione creatrice della musica, Rome 2010.

Gammaitoni M., La funzione sociale del musicista, Rome 2004.

Gammaitoni M. (ed.), Per una sociologia delle arti, storia e storie di vita, Padua 2012.

Gammaitoni M. (ed.), Le arti e la politica, prospettive sociologiche, Padua 2016.

Giannattasio F., Grammatica della musica etnica, Rome 1991.

Greco G., Ponziano R., Musica è comunicazione, Milan 2007.

Green A.-M., De la musique en sociologie, Paris 2006.

Grimaud H., Variazioni selvagge, Turin 2006.

Halbwachs M., La memoria collettiva, Milan 1987.

Hennion A., La passion musicale, Paris 2007.

Leydi R., L'altra musica, etnomusicologia, Milan 2008.

Merriam A.P., Antropologia della musica, Palermo 1983.

Middleton R., Studiare la popular music, Milan 2001.

Perniola M., L'arte espansa, Turin 2015.

Ricci F., Cipriani R., Il consumo musicale in Italia, il caso d egli arrangiamenti, Milan 1989.

Rizzoni C., Fare etnomusicologia oggi, Rome 2011.

Ross A., II resto è rumore, ascoltando il XX secolo, Milan 2009.

Sachs C., Le sorgenti della musica, introduzione all'etnomusicologia, Turin 1979.

Samgati, Il mondo in casa. Storie di una piazza italiana, Rome 2006.

Savonardo L., Sociologia della musica, Turin 2010.

Serravezza A., Sulla nozione di esperienza musicale, Bari 1971.

Shepherd J., Whose music? A sociology of musical languages, New Brunswick and London 1977.

Simmel G., Studi psicologici ed etnologici sulla musica, ed. by M. del Forno, Rome 2008.

Weber M., I Fondamenti Razionali e Sociologici della Musica, in: idem, Economia e Società, Milan 1995.

Zoldberg V., Sociologia dell'arte, Bologna 1990. 